\title{
A comprehensive expression analysis of the MIA gene family in malignancies: MIA gene family members are novel, useful markers of esophageal, lung, and cervical squamous cell carcinoma
}

\author{
Tomonori Sasahira ${ }^{1}$, Tadaaki Kirita ${ }^{2}$, Yukiko Nishiguchi ${ }^{1}$, Miyako Kurihara ${ }^{1,2}$, Chie \\ Nakashima ${ }^{2}$, Anja Katrin Bosserhoff ${ }^{3}$, Hiroki Kuniyasu ${ }^{1}$ \\ ${ }^{1}$ Department of Molecular Pathology, Nara Medical University, Kashihara, Nara, Japan \\ ${ }^{2}$ Department of Oral and Maxillofacial Surgery, Nara Medical University, Kashihara, Japan \\ ${ }^{3}$ Institute for Biochemistry, Friedrich-Alexander University Erlangen-Nürnberg, Erlangen, Germany \\ Correspondence to: Tomonori Sasahira, e-mail: sasa@naramed-u.ac.jp
}

Keywords: MIA, MIA2, TANGO, SCC

Received: January 08, 2016

Accepted: April 11, 2016

Published: April 28, 2016

\section{ABSTRACT}

Melanoma inhibitory activity (MIA) gene family members include MIA, MIA2, and Transport and Golgi organization protein 1 (TANGO). Although MIA gene family members have several tumor-related functions, their detailed roles in malignancies remain poorly elucidated. In this study, 477 tumor specimens were subjected to immunohistochemical screening to evaluate MIA gene family expression. For a validation analysis, we also examined the association between MIA gene family expression and clinicopathological factors in 66 cases of esophageal cancer, 145 cases of lung cancer, and 126 cases of cervical cancer. The frequency of MIA gene family expression was higher among squamous cell carcinomas than among other tumor types subjected to screening. In the validation analysis, MIA gene family staining was observed frequently in esophageal and lung cancers associated with nodal and/ or distant metastasis. In cervical cancers, MIA and TANGO immunostaining also correlated with tumor progression and metastasis. Furthermore, MIA2 expression levels in invasive cervical cancer were upregulated relative to those in cervical intraepithelial neoplasia 3. A disease-free survival analysis revealed that MIA-, MIA2, or TANGO-positive patients had a significantly shorter disease-free survival than did those patients who were negative. Our results suggest that MIA, MIA2, and TANGO may be useful diagnostic and therapeutic molecular targets in human malignancies.

\section{INTRODUCTION}

An estimated 455800 and 527600 new cases and 400200 and 265700 deaths related to esophageal and cervical cancer, respectively, have been reported worldwide [1]. Notably, postoperative recurrences occur in approximately half of all patients with esophageal squamous cell carcinoma (ESCC) [2], and it is the third leading cause of cancer deaths among women in developing countries [1]. Additionally, an estimated 1.8 million new lung cancer cases have occurred worldwide, accounting for approximately $13 \%$ of all cancers [1]. Therefore, the early detection of such malignancies is urgently necessary.

The melanoma inhibitory activity (MIA) gene family includes MIA, MIA2, Transport and Golgi organization protein 1 (TANGO), and otoraplin (OTOR). Members of this family share $34 \%-45 \%$ amino acid homology and $47 \%-59 \%$ cDNA sequence homology and feature a highly conserved SH3-like domain and hydrophobic $\mathrm{N}$-terminal secretory signal sequences [3-6]. Although OTOR expression is highly restricted to healthy eyes, cochlea, and cartilage [7], other members of the MIA gene family have several tumor-related functions. MIA expression correlates with cancer cell detachment, migration, invasion, and apoptotic repression and is accordingly related to malignant tumor progression, metastasis, and poor prognosis [8-12]. MIA2 is induced in liver fibrosis or cirrhosis by activating transforming growth factor-beta (TGF- $\beta$ ) signaling $[13,14]$ and serves as a tumor suppressor in liver cancers following the loss of hepatocyte nuclear factor-1 (HNF-1) expression [15]. However, wild-type MIA2 promotes the loss of 
chemosensitivity in pancreatic cancers, thus worsening an already poor prognosis [16]. Regarding other MIA gene family members, TANGO has been suggested as a tumor suppressor in malignant melanoma, colorectal cancer, and hepatoma $[4,6]$. In summary, the functions of $M I A$ gene family members in malignancies have not been well documented.

We previously reported that MIA gene family members act as oncogenes in oral squamous cell carcinoma (OSCC) [17-20]. For example, MIA expression is enhanced by high-mobility group box 1 (HMGB1) nuclear factor kappa B (NFkB) p65 complexes that bind to the MIA promoter region, thus promoting tumor progression, nodal metastasis, a worse prognosis, angiogenesis, and lymphangiogenesis through the upregulation of vascular endothelial growth factor (VEGF)-A, VEGF-C, and VEGF-D expression $[17,18]$. MIA2 activates MAPK p38, c-Jun N-terminal kinase (JNK), and VEGF family members through its receptors, integrin $\alpha_{4} \beta_{1}$ and $\alpha_{5} \beta_{1}$ [19]. MIA2 expression is also associated with local expansion, nodal metastasis, and inhibited host anti-cancer immunity and apoptosis in OSCC [19]. Furthermore, TANGO promotes angiogenesis and lymphangiogenesis by upregulating platelet-derived growth factor beta polypeptide (PDGFB) and neuropilin 2 in OSCC [20].

Tumor biomarkers have been classified as screening (used diagnostically to identify patients), staging (used to stage disease), prognostic (used to predict outcome), and predictive and monitoring markers (used to speculate and observe clinical responses to any treatment) [21, 22]. Cancer biomarkers must also satisfy the following conditions: (1) the transition can be objectively determined the quality; (2) must be measureable in small sample amounts; (3) must be altered in tumors but not in normal tissues; and (4) must be altered at an early phase of cancer development $[22,23]$. However, the role of MIA gene family as tumor markers in various human malignancies remains controversial. The purpose of this study was to investigate the usefulness of $M I A$ gene family as novel tumor markers in various human neoplastic specimens, including ESCC, lung cancer, and cervical cancer.

\section{RESULTS}

\section{Screening for MIA gene family expression in human tumors}

We initially used immunohistochemistry to examine the expression of MIA gene family members in 477 cases of different tumors. The specificity of the antibodies for MIA gene family was confirmed by Western blotting with recombinant proteins (data not shown). These results are summarized in Table 1. Briefly, higher MIA, MIA2, and TANGO expression levels were observed in $80(16.8 \%)$, $67(14.1 \%)$, and $76(15.9 \%)$ of these cases, respectively. All immunopositive cases exhibited cytoplasmic MIA gene family staining. Several representative images of MIA gene family immunostaining in tumors are shown in Figure $1 \mathrm{~A}$ to $1 \mathrm{I}$.

MIA overexpression was observed in 13 of 30 head and neck SCCs (43.3\%), 4 of 10 ESCCs (40\%), 10 of 35 gastric adenocarcinomas (28.6\%) (Figure 1A), 11 of 35 colorectal adenocarcinomas (31.4\%), 6 of 18 lung SCCs (33.3\%), 1 of 3 cutaneous SCCs (33.3\%), 2 of 7 mammary invasive ductal carcinomas (28.6\%) (Figure 1B), 8 of 21 cervical SCCs (38.1\%), 2 of 6 prostatic adenocarcinomas (33.3\%), and 2 of 8 testicular seminomas (25\%) (Figure 1C). Twelve of the 30 head and neck SCCs $(40 \%), 3$ of 10 ESCCs $(30 \%), 7$ of 16 hepatocellular carcinomas (43.8\%), 2 of 5 pancreatic adenocarcinomas (40\%) (Figure 1E), 5 of 18 lung SCCs (27.8\%), 2 of 10 cutaneous malignant melanomas (20\%), 1 of 3 cutaneous SCCs $(33.3 \%), 6$ of 21 cervical SCCs $(28.6 \%), 3$ of 11 endometrial endometrioid adenocarcinomas (27.3\%), and 5 of 13 renal cell carcinoma (38.5\%) (Figure 1F) exhibited excessive MIA2 immunoreactivity. Elevated TANGO expression levels were detected in 10 of 30 head and neck SCCs (33.3\%), 3 of 10 ESCCs (30\%), 8 of 35 colorectal adenocarcinomas $(22.9 \%), 1$ of 5 pancreatic adenocarcinomas (20\%), 6 of 18 lung SCCs $(33.3 \%)$, 2 of 10 cutaneous malignant melanomas (20\%), 1 of 3 cutaneous SCCs (33.3\%), 3 of 7 mammary invasive ductal carcinomas (32.9\%), 7 of 21 cervical SCCs (33.3\%), 3 of 11 endometrial endometrioid adenocarcinomas (27.3\%) (Figure 1G), 2 of 6 prostatic adenocarcinomas (33.3\%), 2 of 8 testicular seminomas (25\%), and 4 of 12 papillary thyroid carcinomas $(33.3 \%)$ (Figure 1I). MIA2 and TANGO immunostaining in a colonic adenocarcinoma and ovarian serous adenocarcinoma are shown in Figure 1D and $1 \mathrm{H}$, respectively. Overall, SCCs were more likely to express MIA gene family members. Detailed MIA, MIA2, and TANGO immunohistochemistry results in other human malignant tumors are presented in Table 1.

We formerly reported that MIA, MIA2, and TANGO act as oncogenes in OSCC [17-20]; however, the significance of MIA gene family expression in SCCs of other organs, such as the esophagus, cervix, and lung, has not been clarified. Accordingly, we next inspected the relationship between MIA gene family immunostaining and clinicopathological features in those malignancies.

\section{Relationship MIA gene family expression and clinicopathological parameters in esophageal cancers}

Compared with non-tumor esophageal epithelium, ESCC tissues were more likely to exhibit subcellular MIA gene family expression. MIA, MIA2, and TANGO overexpression was detected in $33.3 \%(22 / 66), 30.3 \%$ $(20 / 66)$, and $27.3 \%(18 / 66)$ of ESCC cases, respectively (Figure 2A-2C). Further, co-expression rate of MIA and MIA2, MIA and TANGO, MIA2 and TANGO, 
and all molecules were $15.2 \%(10 / 66), 16.7 \%(11 / 66)$, $13.6 \%(9 / 66)$, and $9.1 \%(6 / 66)$, respectively. The correlations between MIA gene family expression and clinicopathological parameters are summarized in Table 2. MIA upregulation correlated only with nodal metastasis, and 15 of $32(46.9 \%)$ patients with nodal metastasis exhibited MIA immunopositivity $(P=0.0362)$. On the other hand, MIA2 expression correlated significantly with the clinical stage $(P=0.0026)$, local tumor cell progression (T classification; $P=0.0076$ ), and nodal metastasis $(P=0.0069)$. Furthermore, TANGO expression was observed in 14 of $32(43.8 \%)$ and 9 of $13(69.2 \%)$ cases involving nodal or distant metastasis, respectively, with lower rates among patients with no nodal progression $(4 / 34,11.8 \% ; P=0.0053)$ or distant metastasis $(9 / 53$, $17 \% ; P=0.0005)$. No strong relationships of MIA, MIA2, or TANGO expression with other clinicopathological characteristics were found in ESCC cases.

\section{Association between MIA gene family expression and clinicopathological characteristics in lung cancers}

A summary of the results pertaining to lung cancer is shown in Table 3. Non-cancerous lungs did not overexpress MIA gene family members; in contrast, cytoplasmic MIA, MIA2, and TANGO expression was found in $49(33.8 \%)$, $45(31 \%)$ and $47(32.4 \%)$ of the 145 cases, respectively (Figure 3A-3F). Additionally, co-expression rate of MIA and MIA2, MIA and TANGO, MIA2 and TANGO, and all molecules were $24.8 \%(36 / 145), 17.2 \%(25 / 145)$, $19.3 \%$ (28/145), and 13.8\% (20/145), respectively. Strong MIA, MIA2, and TANGO immunoreactivity levels were detected in $41 \%(43 / 105), 37.1 \%(39 / 105)$, and $40 \%$ (42/105) of SCCs, respectively; notably, the MIA, MIA2, and TANGO expression frequencies in adenocarcinomas, small cell carcinomas, and LCNECs were significantly
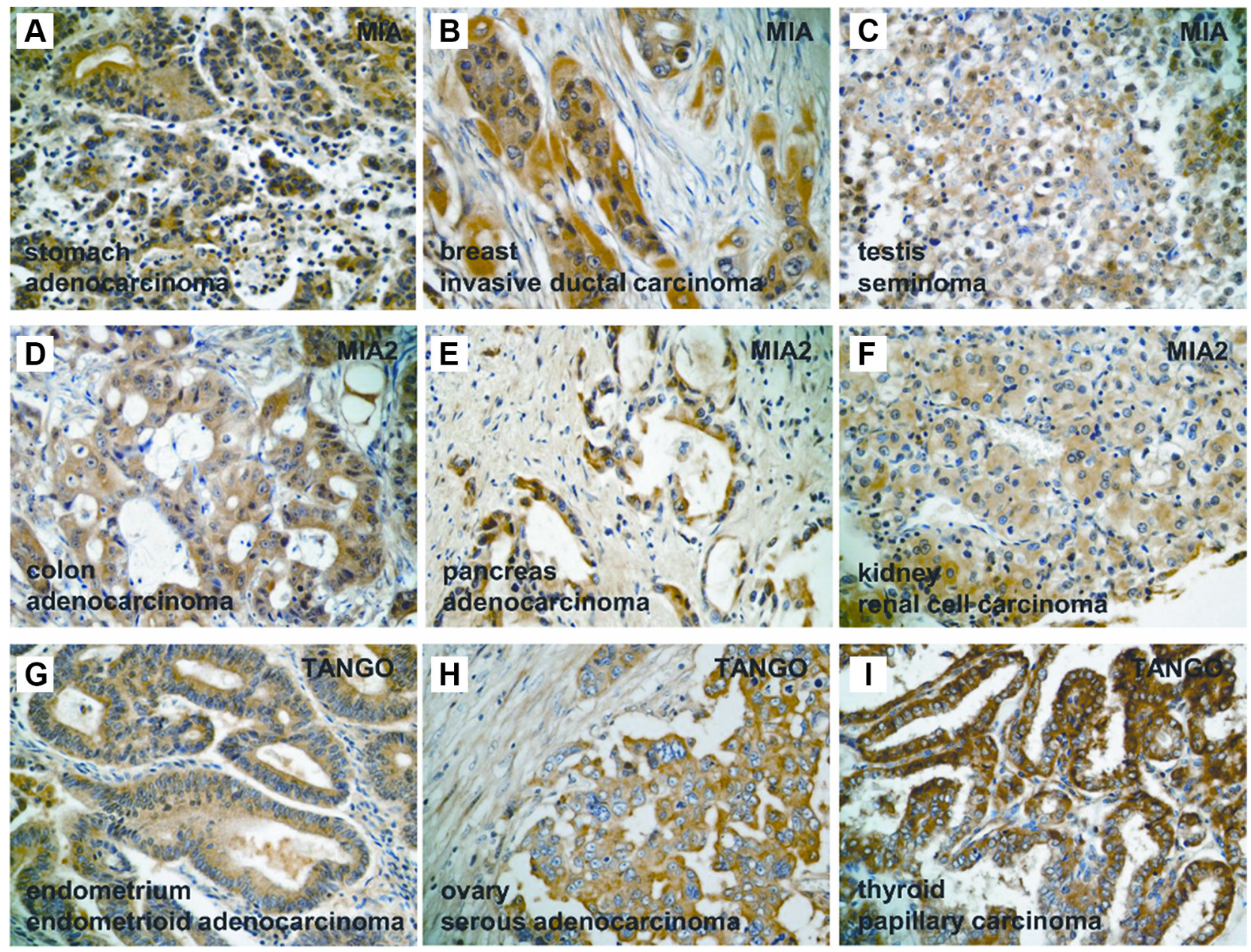

Figure 1: Expression of $\boldsymbol{M I A}$ gene family in human tumors. (A-C) Immunostaining of MIA in human tumors. Cytoplasmic expression of MIA was detected in chondrosarcoma of the bone (A), invasive ductal carcinoma of the breast (B), and seminoma of the testis (C). (D-F) Immunostaining of MIA2 in human tumors. Cytoplasmic localization of MIA2 was found in colonic adenocarcinoma (D), pancreatic adenocarcinoma (E), and renal cell carcinoma (F). (G-I) Immunostaining of TANGO in human tumors. Cytoplasmic staining of TANGO was observed in endometrial endometriod adenocarcinoma $(\mathrm{G})$, ovarian serous cystadenocarcinoma $(\mathrm{H})$, and papillary carcinoma of the thyroid (I). Original magnification, 400 fold. 

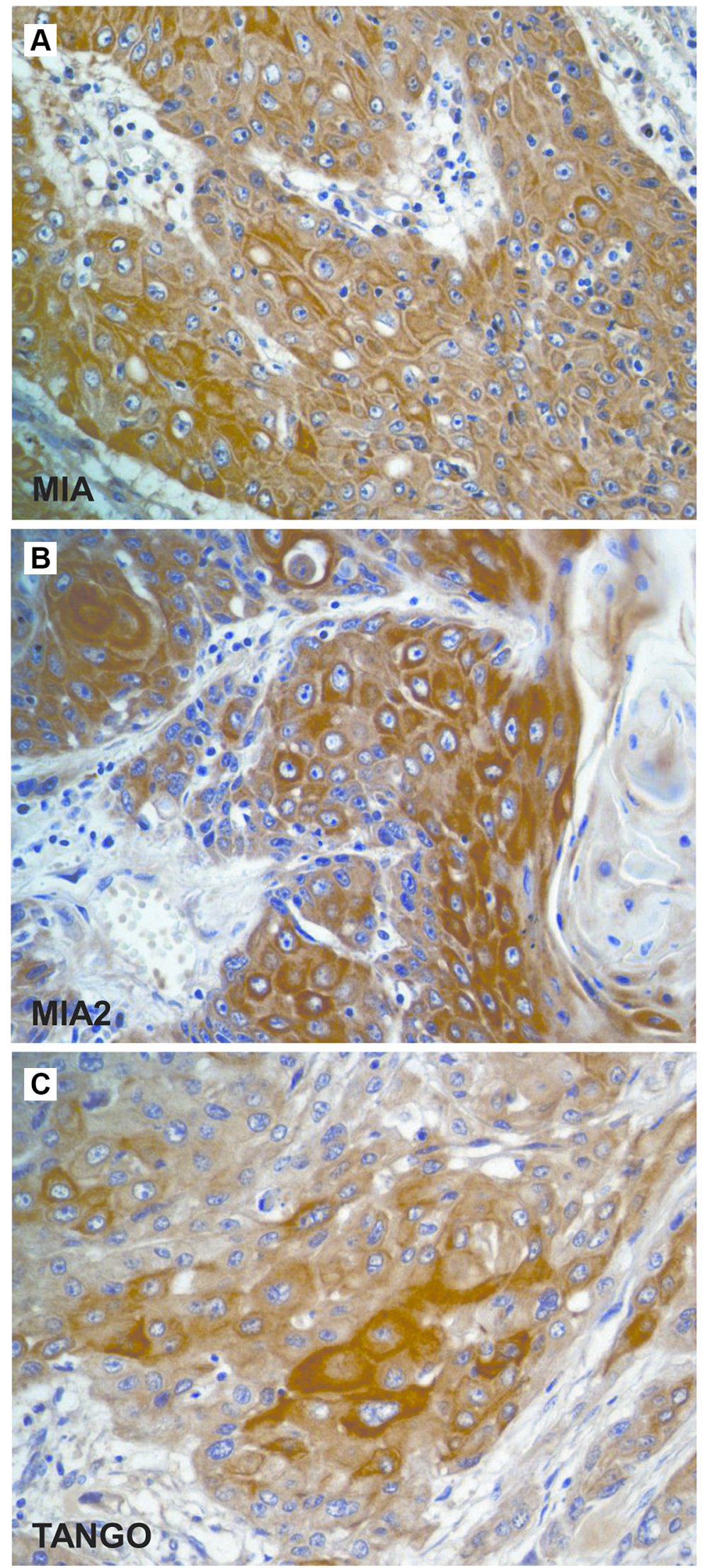

Figure 2: Immunostaining of the MIA gene family in esophageal cancer. (A-C) Immunohistochemistry of the MIA gene family in human ESCC. Immunostaining of MIA (A), MIA2 (B), and TANGO (C) was detected in the cytoplasm of ESCC cells. Original magnification, 400 fold. ESCC: esophageal squamous cell carcinoma. 
Table 1: Expression of MIA gene family in human tumors

\begin{tabular}{|c|c|c|c|c|}
\hline \multirow[b]{2}{*}{ Organ and histology } & \multirow[b]{2}{*}{ Number of cases } & \multicolumn{3}{|c|}{ Number of overexpression cases } \\
\hline & & MIA & MIA2 & TANGO \\
\hline \multicolumn{5}{|c|}{ Head and neck (oral cavity, larynx, pharynx) } \\
\hline Squamous cell carcinoma & 30 & $13(43.3 \%)$ & $12(40 \%)$ & $10(33.3 \%)$ \\
\hline Others & 6 & $0(0 \%)$ & $0(0 \%)$ & $0(0 \%)$ \\
\hline \multicolumn{5}{|l|}{ Salivary gland } \\
\hline Acinic cell carcinoma & 3 & $0(0 \%)$ & $0(0 \%)$ & $1(33.3 \%)$ \\
\hline Adenoid cystic carcinoma & 3 & $1(33.3 \%)$ & $1(33.3 \%)$ & $1(33.3 \%)$ \\
\hline Mucoepidermoid carcinoma & 2 & $0(0 \%)$ & $0(0 \%)$ & $0(0 \%)$ \\
\hline Others & 7 & $1(14.3 \%)$ & $0(0 \%)$ & $0(0 \%)$ \\
\hline \multicolumn{5}{|l|}{ Esophagus } \\
\hline Squamous cell carcinoma & 10 & $4(40 \%)$ & $4(40 \%)$ & $4(40 \%)$ \\
\hline \multicolumn{5}{|l|}{ Stomach } \\
\hline Adenocarcinoma & 35 & $10(28.6 \%)$ & $5(14.3 \%)$ & $6(17.1 \%)$ \\
\hline \multicolumn{5}{|l|}{ Small intestine } \\
\hline Gastrointestinal stromal tumor & 5 & $0(0 \%)$ & $0(0 \%)$ & $0(0 \%)$ \\
\hline \multicolumn{5}{|l|}{ Colorectum } \\
\hline Adenocarcinoma & 35 & $11(31.4 \%)$ & $6(17.1 \%)$ & $8(22.9 \%)$ \\
\hline \multicolumn{5}{|l|}{ Liver } \\
\hline Hepatocellular carcinoma & 16 & $0(0 \%)$ & $7(43.8 \%)$ & $3(18.8 \%)$ \\
\hline \multicolumn{5}{|l|}{ Biliary system } \\
\hline Adenocarcinoma & 10 & $1(10 \%)$ & $2(20 \%)$ & $1(10 \%)$ \\
\hline \multicolumn{5}{|l|}{ Pancreas } \\
\hline Adenocarcinoma & 5 & $0(0 \%)$ & $2(40 \%)$ & $1(20 \%)$ \\
\hline \multicolumn{5}{|l|}{ Lung } \\
\hline Squamous cell carcinoma & 18 & $6(33.3 \%)$ & $5(27.8 \%)$ & $6(33.3 \%)$ \\
\hline Adenocarcinoma & 11 & $2(18.2 \%)$ & $2(18.2 \%)$ & $2(18.2 \%)$ \\
\hline Others & 4 & $0(0 \%)$ & $0(0 \%)$ & $0(0 \%)$ \\
\hline \multicolumn{5}{|l|}{ Soft tissue } \\
\hline Liposarcoma & 12 & $0(0 \%)$ & $0(0 \%)$ & $0(0 \%)$ \\
\hline Undifferentiated pleomorphic sarcoma & 4 & $0(0 \%)$ & $0(0 \%)$ & $0(0 \%)$ \\
\hline Others & 9 & $0(0 \%)$ & $0(0 \%)$ & $0(0 \%)$ \\
\hline \multicolumn{5}{|l|}{ Bone } \\
\hline Chondrosarcoma & 8 & $4(50 \%)$ & $0(0 \%)$ & $0(0 \%)$ \\
\hline Osteosarcoma & 3 & $0(0 \%)$ & $0(0 \%)$ & $0(0 \%)$ \\
\hline Others & 5 & $0(0 \%)$ & $0(0 \%)$ & $0(0 \%)$ \\
\hline \multicolumn{5}{|l|}{ Skin } \\
\hline Malignant melanoma & 10 & $6(60 \%)$ & $2(20 \%)$ & $2(20 \%)$ \\
\hline Squamous cell carcinoma & 3 & $1(33.3 \%)$ & $1(33.3 \%)$ & $1(33.3 \%)$ \\
\hline \multicolumn{5}{|l|}{ Breast } \\
\hline Invasive ductal carcinoma & 7 & $2(28.6 \%)$ & $0(0 \%)$ & $3(42.9 \%)$ \\
\hline Invasive lobular carcinoma & 4 & $0(0 \%)$ & $1(25 \%)$ & $1(25 \%)$ \\
\hline Others & 8 & $0(0 \%)$ & $0(0 \%)$ & $0(0 \%)$ \\
\hline
\end{tabular}




\begin{tabular}{|c|c|c|c|c|}
\hline \multicolumn{5}{|l|}{ Uterine cervix } \\
\hline Squamous cell carcinoma & 21 & $8(38.1 \%)$ & $6(28.6 \%)$ & $7(33.3 \%)$ \\
\hline Others & 5 & $0(0 \%)$ & $0(0 \%)$ & $0(0 \%)$ \\
\hline \multicolumn{5}{|l|}{ Endometrium } \\
\hline Endometrioid adenocarcinoma & 11 & $0(0 \%)$ & $3(27.3 \%)$ & $3(27.3 \%)$ \\
\hline Others & 1 & $0(0 \%)$ & $0(0 \%)$ & $0(0 \%)$ \\
\hline \multicolumn{5}{|l|}{ Ovary } \\
\hline Serous adenocarcinoma & 11 & $2(18.2 \%)$ & $1(9.1 \%)$ & $2(18.2 \%)$ \\
\hline Mucinous adenocarcinoma & 8 & $0(0 \%)$ & $1(12.5 \%)$ & $1(12.5 \%)$ \\
\hline Endometrioid adenocarcinoma & 5 & $1(20 \%)$ & $0(0 \%)$ & $1(20 \%)$ \\
\hline Clear cell carcinoma & 4 & $0(0 \%)$ & $0(0 \%)$ & $0(0 \%)$ \\
\hline Dysgerminoma & 4 & $0(0 \%)$ & $0(0 \%)$ & $1(25 \%)$ \\
\hline Others & 15 & $1(6.7 \%)$ & $0(0 \%)$ & $0(0 \%)$ \\
\hline \multicolumn{5}{|l|}{ Prostate } \\
\hline Adenocarcinoma & 6 & $2(33.3 \%)$ & $0(0 \%)$ & $2(33.3 \%)$ \\
\hline \multicolumn{5}{|l|}{ Testis } \\
\hline Seminoma & 8 & $2(25 \%)$ & $0(0 \%)$ & $2(25 \%)$ \\
\hline Others & 3 & $0(0 \%)$ & $0(0 \%)$ & $0(0 \%)$ \\
\hline \multicolumn{5}{|l|}{ Urinary bladder } \\
\hline Urothelial carcinoma & 17 & $2(11.8 \%)$ & $1(5.9 \%)$ & $3(17.7 \%)$ \\
\hline \multicolumn{5}{|l|}{ Kidney } \\
\hline Renal cell carcinoma & 13 & $0(0 \%)$ & $5(38.5 \%)$ & $0(0 \%)$ \\
\hline Others & 3 & $0(0 \%)$ & $0(0 \%)$ & $0(0 \%)$ \\
\hline \multicolumn{5}{|l|}{ Thyroid } \\
\hline Papillary carcinoma & 12 & $0(0 \%)$ & $0(0 \%)$ & $4(33.3 \%)$ \\
\hline Others & 3 & $0(0 \%)$ & $0(0 \%)$ & $0(0 \%)$ \\
\hline \multicolumn{5}{|l|}{ Adrenal gland } \\
\hline Cortical carcinoma & 10 & $0(0 \%)$ & $0(0 \%)$ & $1(10 \%)$ \\
\hline Pheochromocytoma & 3 & $0(0 \%)$ & $0(0 \%)$ & $0(0 \%)$ \\
\hline Others & 2 & $0(0 \%)$ & $0(0 \%)$ & $0(0 \%)$ \\
\hline \multicolumn{5}{|l|}{ Lymphoid tissue } \\
\hline Malignant lymphoma & 20 & $0(0 \%)$ & $0(0 \%)$ & $0(0 \%)$ \\
\hline Other tissues & 19 & $0(0 \%)$ & $0(0 \%)$ & $0(0 \%)$ \\
\hline
\end{tabular}

lower than those in SCCs (Figure 3A-3F; $P=0.0307$, $P=0.0453$, and $P=0.0173$, respectively). Higher MIA (21/36, 58.3\%), MIA2 (19/36, 52.8\%), and TANGO expression levels $(21 / 36,58.3 \%)$ were observed in cases with nodal metastasis relative to those without lymph node involvement $(P=0.0005, P=0.0018$, and $P=0.0004$, respectively). MIA and MIA2 expression also correlated with distant metastasis; 11 of 17 (64.7\%) patients with distant metastases exhibited MIA and MIA2 immunopositivity ( $P=0.0063$ and $P=0.0036$, respectively). Moreover, TANGO expression correlated significantly with the T classification $(P=0.0177)$. There were no significant relationships between MIA gene family expression and other clinicopathological parameters in lung cancers.

\section{Correlation between MIA gene family expression and clinicopathological features in cervical cancers}

The detailed immunohistochemical results of the 126 cervical cancers selected for the second cohort are summarized in Table 4. Non-tumor cervical mucosal samples had negative or very weak MIA gene family expression, whereas $34.1 \%(43 / 126), 31 \%$ (39/126), and $30.2 \%(38 / 126)$ of cervical cancer cases exhibited cytoplasmic MIA, MIA2, and TANGO staining, respectively (Figure 4A-4D). Moreover, co-expression rate of MIA and MIA2, MIA and TANGO, MIA2 and TANGO, and all molecules were $13.5 \%$ (17/126), 
Table 2: Relationship between expression of MIAgene family and clinicopathological characteristics in ESCC

\begin{tabular}{|c|c|c|c|c|c|c|}
\hline \multirow[b]{2}{*}{ Parameters } & \multicolumn{2}{|c|}{ MIA } & \multicolumn{2}{|c|}{ MIA2 } & \multicolumn{2}{|c|}{ TANGO } \\
\hline & negative & positive & negative & positive & negative & positive \\
\hline \multicolumn{7}{|l|}{ Gender } \\
\hline Male & 31 & 18 & 37 & 12 & 34 & 15 \\
\hline Female & 13 & 4 & 9 & 8 & 14 & 3 \\
\hline$P$ value & 0.3836 & & 0.1244 & & 0.3614 & \\
\hline \multicolumn{7}{|l|}{ Age } \\
\hline$<-65$ & 14 & 8 & 13 & 9 & 17 & 5 \\
\hline$>65$ & 30 & 14 & 33 & 11 & 31 & 13 \\
\hline$P$ value & 0.7848 & & 0.2565 & & 0.7702 & \\
\hline \multicolumn{7}{|l|}{ Alcohol intake } \\
\hline Habitual drinking & 24 & 16 & 25 & 15 & 26 & 14 \\
\hline Social drinking & 14 & 6 & 16 & 4 & 16 & 4 \\
\hline No drinking & 6 & 0 & 5 & 1 & 6 & 0 \\
\hline$P$ value & 0.1423 & & 0.2844 & & 0.1362 & \\
\hline \multicolumn{7}{|c|}{ Histological differentiation* } \\
\hline Well & 23 & 14 & 25 & 12 & 26 & 11 \\
\hline Mod, Por & 21 & 8 & 21 & 8 & 22 & 7 \\
\hline$P$ value & 0.4381 & & 0.7894 & & 0.7817 & \\
\hline \multicolumn{7}{|l|}{ Clinical stage } \\
\hline I-II & 25 & 9 & 28 & 6 & 28 & 6 \\
\hline III-IV & 19 & 13 & 18 & 14 & 20 & 12 \\
\hline$P$ value & 0.2978 & & 0.0317 & & 0.0983 & \\
\hline \multicolumn{7}{|l|}{$\mathrm{T}$ classification } \\
\hline $\mathrm{T} 1-2$ & 22 & 8 & 26 & 4 & 24 & 6 \\
\hline T3-4 & 22 & 14 & 20 & 16 & 24 & 12 \\
\hline$P$ value & 0.4320 & & 0.0076 & & 0.2748 & \\
\hline \multicolumn{7}{|l|}{ Nodal metastasis } \\
\hline Negative & 27 & 7 & 29 & 5 & 30 & 4 \\
\hline Positive & 17 & 15 & 17 & 15 & 18 & 14 \\
\hline P value & 0.0362 & 0.0069 & 0.0053 & & & \\
\hline \multicolumn{7}{|l|}{ Distant metastasis } \\
\hline Negative & 37 & 16 & 38 & 15 & 44 & 9 \\
\hline Positive & 7 & 6 & 8 & 5 & 4 & 9 \\
\hline$P$ value & 0.3313 & & 0.5117 & & 0.0005 & \\
\hline
\end{tabular}

Relationship between expression of MIA gene family and parameters were calculated by Fischer's exact test. T classification and clinical stage were classified according to the TNM classification.

*Histological differentiation: Well, well-differentiated squamous cell carcinoma; Mod, moderately differentiated squamous cell carcinoma; Por, poorly differentiated squamous cell carcinoma.

$10.3 \%(13 / 126), 12.7 \%(16 / 126)$, and $7.9 \%(10 / 126)$, respectively. In cervical cancers, increased MIA expression correlated strongly with the clinical stage $(P=0.0177)$, T classification $(P=0.0185)$, and lymph node metastasis $(P=0.0477)$. No obvious correlations were identified between the level of MIA and TANGO expression and tumor histological type; in contrast, the MIA2 expression levels increased from CIN3 $(1 / 15,6.7 \%)$ to invasive SCC $(38 / 111,34.2 \% ; P=0.0361$; Figure 4B, 4C). TANGO overexpression was more frequent in cases with nodal 
Table 3: Relationship between expression of MIA gene family and clinicopathological characteristics in lung cancer

\begin{tabular}{|c|c|c|c|c|c|c|}
\hline \multirow[b]{2}{*}{ Parameters } & \multicolumn{2}{|c|}{ MIA } & \multicolumn{2}{|c|}{ MIA2 } & \multicolumn{2}{|c|}{ TANGO } \\
\hline & negative & positive & negative & positive & negative & positive \\
\hline \multicolumn{7}{|l|}{ Gender } \\
\hline Male & 69 & 38 & 71 & 36 & 69 & 38 \\
\hline Female & 27 & 11 & 29 & 9 & 29 & 9 \\
\hline$P$ value & 0.5512 & & 0.3101 & & 0.2276 & \\
\hline \multicolumn{7}{|l|}{ Age } \\
\hline$<-65$ & 47 & 20 & 49 & 18 & 47 & 20 \\
\hline$>65$ & 49 & 29 & 51 & 27 & 51 & 27 \\
\hline$P$ value & 0.3827 & & 0.3696 & & 0.5957 & \\
\hline \multicolumn{7}{|l|}{ Smoking habit } \\
\hline Yes & 63 & 39 & 67 & 35 & 64 & 38 \\
\hline No & 33 & 10 & 33 & 10 & 34 & 9 \\
\hline$P$ value & 0.0879 & & 0.2394 & & 0.0796 & \\
\hline \multicolumn{7}{|l|}{ Histology * } \\
\hline SCC & 62 & 43 & 66 & 39 & 63 & 42 \\
\hline Adeno & 21 & 4 & 20 & 5 & 22 & 3 \\
\hline Small & 9 & 1 & 10 & 0 & 9 & 1 \\
\hline LCNEC & 4 & 1 & 4 & 1 & 4 & 1 \\
\hline$P$ value & 0.0307 & & 0.0453 & & 0.0173 & \\
\hline \multicolumn{7}{|l|}{ Clinical stage } \\
\hline I & 18 & 13 & 24 & 8 & 26 & 6 \\
\hline II & 43 & 20 & 42 & 21 & 45 & 18 \\
\hline III-IV & 34 & 16 & 34 & 16 & 27 & 23 \\
\hline$P$ value & 0.5766 & & 0.6971 & & 0.0252 & \\
\hline \multicolumn{7}{|l|}{$\mathrm{T}$ classification } \\
\hline $\mathrm{T} 1$ & 19 & 13 & 24 & 8 & 26 & 6 \\
\hline $\mathrm{T} 2$ & 38 & 18 & 36 & 20 & 41 & 15 \\
\hline T3-4 & 39 & 18 & 40 & 17 & 31 & 26 \\
\hline$P$ value & 0.6503 & & 0.5609 & & 0.0177 & \\
\hline \multicolumn{7}{|c|}{ Nodal metastasis } \\
\hline Negative & 81 & 28 & 83 & 26 & 83 & 26 \\
\hline Positive & 15 & 21 & 17 & 19 & 15 & 21 \\
\hline$P$ value & 0.0005 & & 0.0018 & & 0.0004 & \\
\hline \multicolumn{7}{|c|}{ Distant metastasis } \\
\hline Negative & 90 & 38 & 94 & 34 & 87 & 41 \\
\hline Positive & 6 & 11 & 6 & 11 & 11 & 6 \\
\hline$P$ value & 0.0063 & & 0.0036 & & 0.7876 & \\
\hline
\end{tabular}

Relationship between expression of MIA gene family and parameters were calculated by Fischer's exact test or chi-square test. T classification and clinical stage were classified according to the TNM classification.

*Histology: SCC, squamous cell carcinoma; adeno, adenocarcinoma; small, small cell carcinoma; LCNEC, large cell neuroendocrine cell carcinoma. 
metastasis $(7 / 11,63.6 \%)$ or distant metastasis than in those without metastasis $(31 / 115,27 \% ; P=0.0175)$. In addition, TANGO immunostaining was observed in $83.3 \%$ $(5 / 6)$ of cases with distant metastasis and only $27.5 \%$
$(33 / 120)$ of cases without distant metastasis $(P=0.0095)$ No significant difference was observed between $M I A$ gene family expression and other clinicopathological features in cervical cancers.
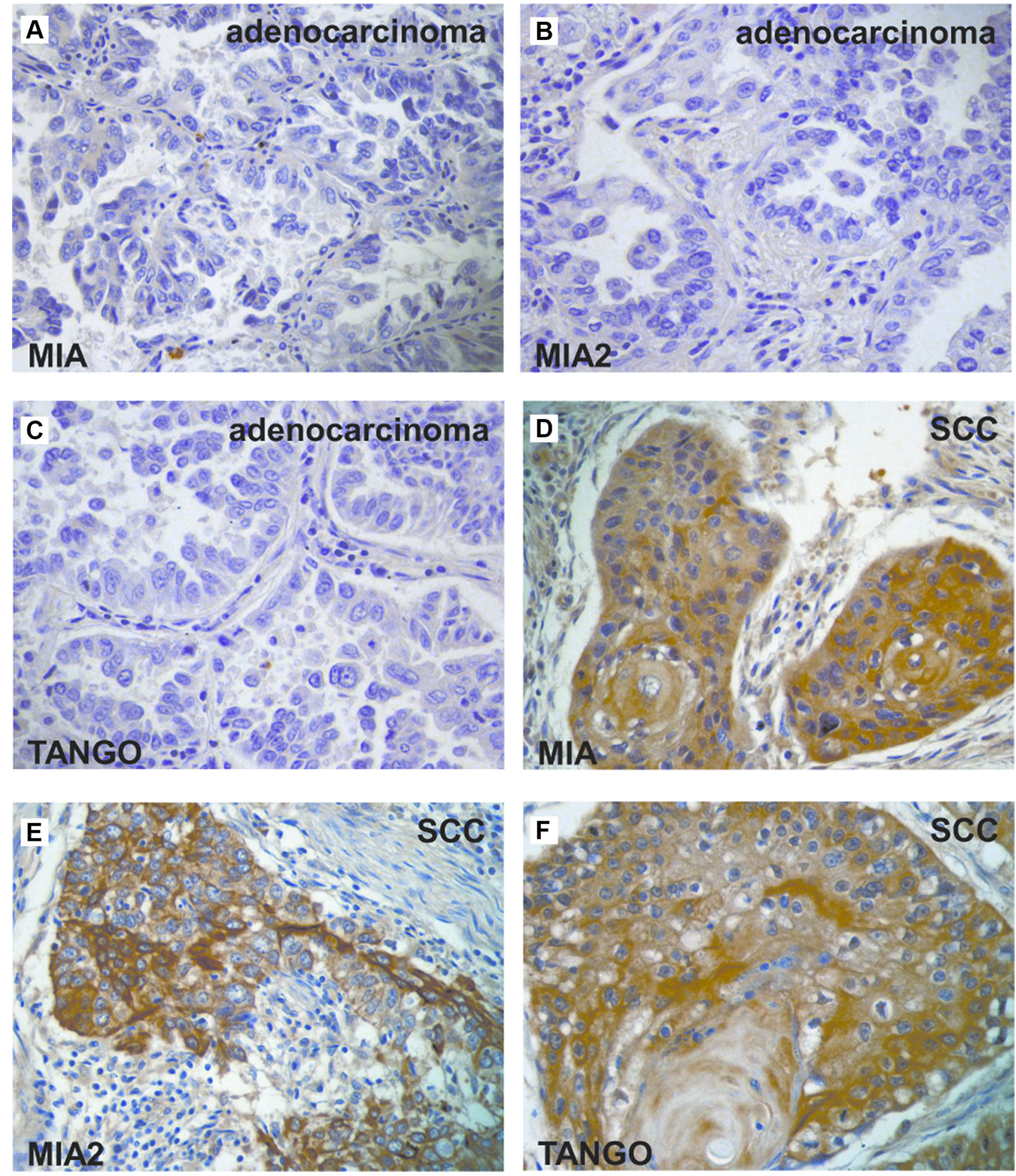

Figure 3: Expression of the $\boldsymbol{M I A}$ gene family in lung cancer. (A-C) Immunohistochemical analysis of the $M I A$ gene family in adenocarcinoma. Expression of MIA(A), MIA2 (B), and TANGO (C) was not detected in lung adenocarcinoma. (D-F) Immunohistochemistry of the MIA gene family in SCC. Cytoplasmic localization of MIA (D), MIA2 (e), and TANGO (F) was observed in lung SCC. Original magnification, 400 fold. SCC: squamous cell carcinoma. 


\section{Gene expression of MIA gene family and secretion of MIA in esophageal, lung, and cervical cancers}

Next, we verified the expression of MIA family genes in cases with esophageal, lung, and cervical cancers. In malignancies, expression levels of MIA, MIA2, and $T A N G O$ were significantly higher than in non-tumorous specimens (Figure 5A). Moreover, the expression of MIA family genes was significantly associated with immunohistochemical grade in esophageal, lung, and cervical cancers (Figure 5B). Expression levels of $M I A$ gene family in primary tumor and metastatic sites remained unchanged (data not shown).

Next, MIA gene family expression levels were compared between serum samples and tumor specimens. Serum secretion levels of MIA measured by enzymelinked immunosorbent assay (ELISA) were well correlated with those of tumor expression levels quantified by quantitative (qRT-PCR) (Figure 5C).

\section{Disease free survival analysis of esophageal, lung, and cervical cancers}

Finally, we conducted a Kaplan-Meier survival analysis. We found that patients with ESCC whose samples exhibited positive MIA, MIA2, and TANGO immunostaining had significantly shorter disease-free survival intervals, compared to patients with negative expression $(P<0.0001, P=0.0135$, and $P=0.0131$, respectively; Figure 6A-6C). Among patients with lung cancer, those with MIA, MIA2, and TANGO-positive samples had a significantly worse disease free survival than did those with negative samples $(P<0.0001, P<$ 0.0001 , and $P=0.0006$, respectively; Figure $6 \mathrm{D}-6 \mathrm{~F})$. Furthermore, MIA $(P<0.0001)$, MIA2 $(P=0.0144)$, and TANGO expression $(P=0.0151)$ were associated with a poor prognosis among patients with cervical cancer (Figure 6G-6I).

\section{DISCUSSION}

Although $M I A$ gene family members serve several tumor-related functions, to our knowledge, this is the first report to subject a variety of human malignancies to semicomprehensive immunohistochemical MIA gene family expression profiling. In this investigation, we found that MIA gene family members are frequently expressed in several types of human tumors, including SCCs. We also confirmed the significance of MIA gene family expression in ESCC, lung cancer, and cervical cancer. In particular, cases of ESCC and lung cancer with nodal and/or distant
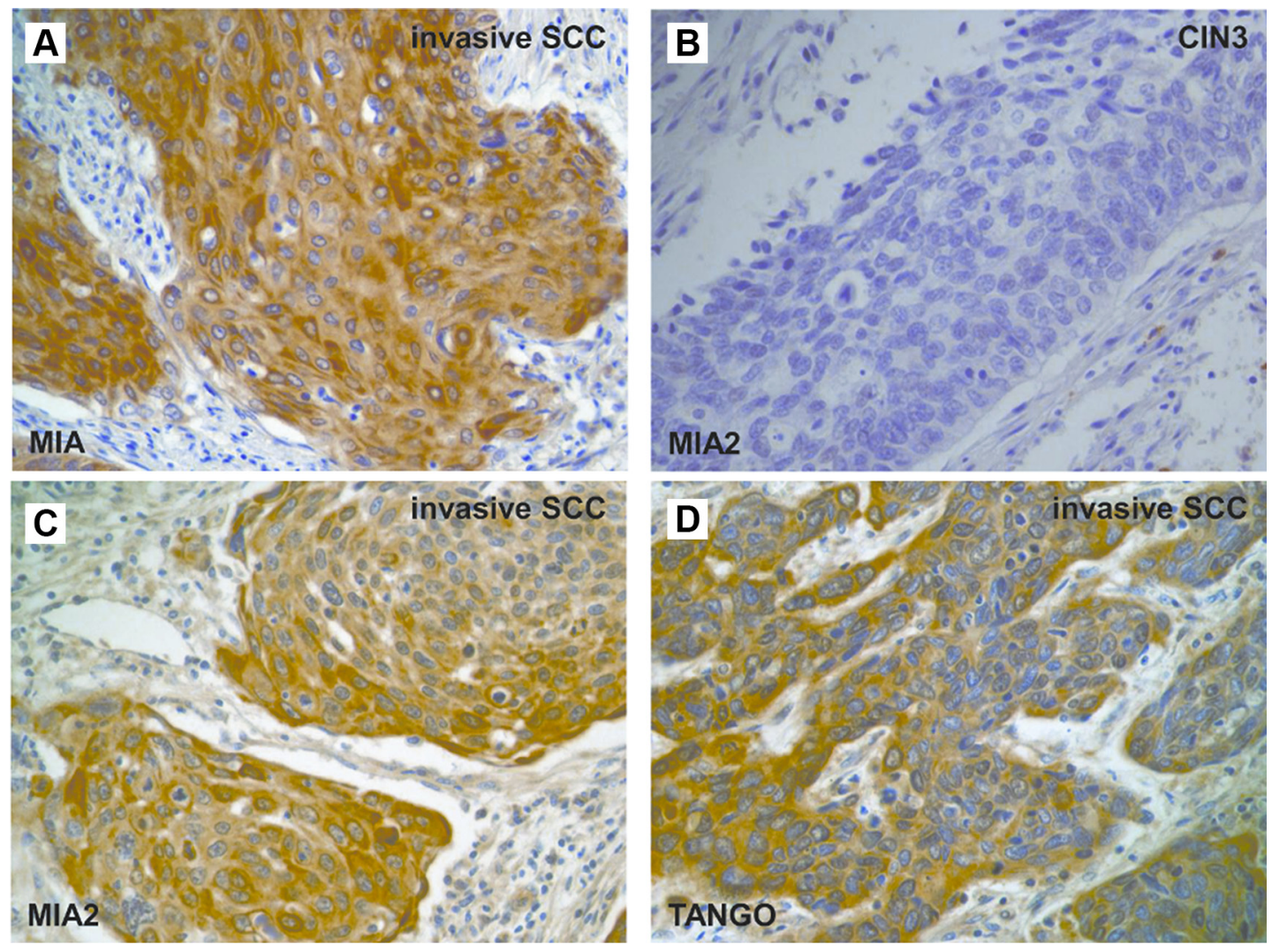

Figure 4: Expression of the $\boldsymbol{M I A}$ gene family in cervical cancer. (A, C-D) Immunostaining of the $M I A$ gene family in invasive SCC. MIA (A), MIA2 (C), and TANGO (D) expression were observed in the cytoplasm of invasive cervical SCC. (B) Cases with CIN3 showed no immunoreactivity of MIA2. Original magnification, 400 fold. SCC: squamous cell carcinoma. 
metastases were frequently positive for $M I A$ gene family expression; similarly, lung SCCs were frequently positive for these proteins. In addition, $M I A$ gene family expression was also associated with a poor prognosis among cancer patients. However, further research is needed to determine the association between $M I A$ gene family expression and clinicopathological significance in tumors. TMA has recently become as powerful tool for large-scale expression analysis. TMA immunohistochemistry is a valuable high-throughput analysis technique because it eliminates technical variations among cases by subjecting all tissue cores to equal immunostaining conditions [24]. Additional immunohistochemical analyses of $M I A$ gene family expression using large numbers of TMA slides will likely be effective.

In the present study, we have demonstrated the expression of MIA in previously uninvestigated tumors.
Notably, MIA promotes cell detachment, migration, and invasion and suppresses cancer cell apoptosis and lymphokine activated killer cell (LAK) infiltration. In addition, MIA is a ligand for the cell surface receptors integrin $\alpha_{4} \beta_{1} / \alpha_{5} \beta_{1}$ and binds to fibronectin via SH3 domain-like structures to inhibit cell-to-stromal adhesion $[9,25,26]$. In a previous report, we described the activation of MIA via interactions of intracellular HMGB1 with NFkBp65 and observed the strong implication of MIA in tumor progression and nodal metastasis through the induction of angiogenesis and lymphangiogenesis in OSCC $[17,18]$. MIA expression has also been observed in malignant melanoma, gastric cancer, pancreatic cancer, breast cancer, chondrosarcoma, glioma, and OSCC [7-12, 17, 18, 27-30].

Several reports have revealed that MIA2 and TANGO can act as tumor suppressors [4-6, 15]; it is
A

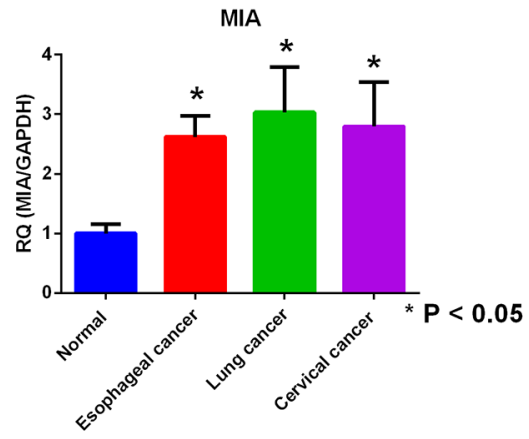

B

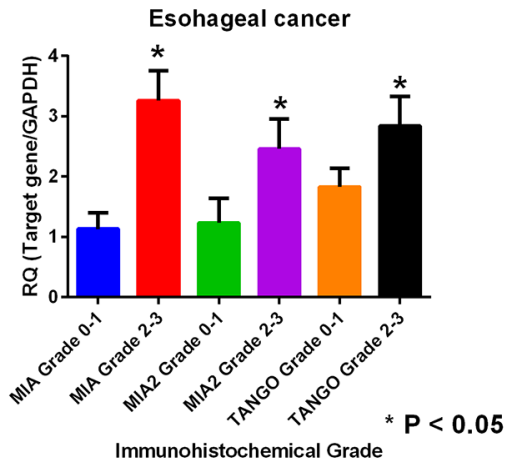

C

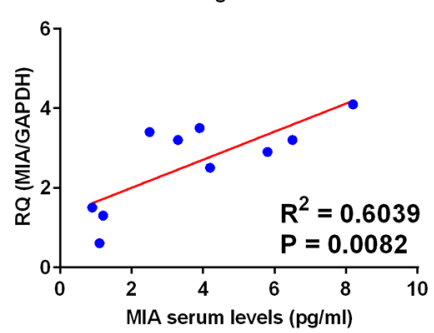

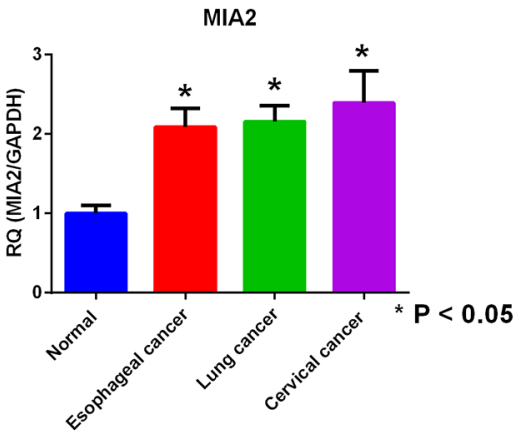
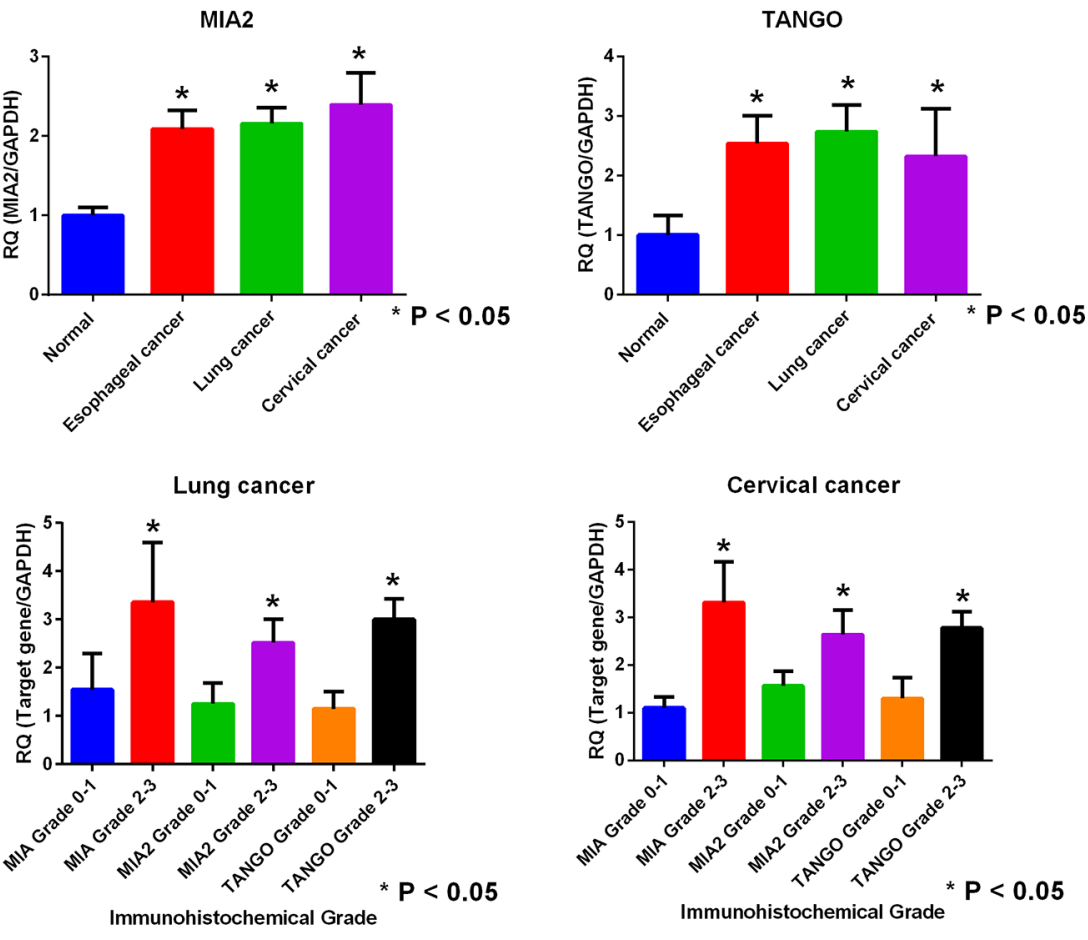

Lung cancer

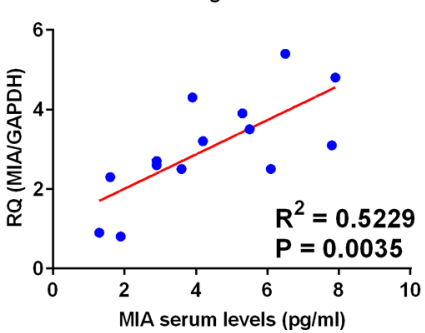

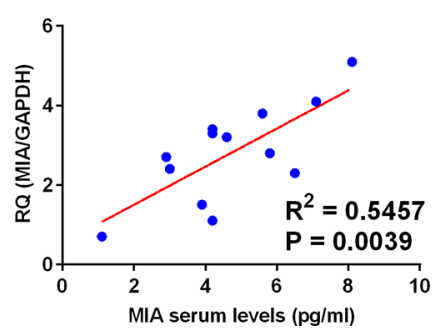

Cervical cancer

Figure 5: Gene expression and secretion of the $M I A$ gene family in esophageal, lung, and cervical cancer. (A) Expression of MIA, MIA2, and TANGO in esophageal, lung, and cervical cancer by real-time RT-PCR. Normal esophageal, lung, and cervical tissues were set as 1. Expression levels of MIA, MIA2, and TANGO in malignancies were higher than normal tissues. (B) Association of MIA, MIA2, or TANGO expression with immunohistochemical grade in cases with esophageal, lung, and cervical cancer. In malignancies, expression levels of each genes were well correlated with immunohistochemical grade. (C) Comparison of MIA levels with serum and primary tumor. Tumor expression levels of MIA were significantly correlated with those of serum secretion levels in esophageal, lung, and cervical cancer. Error bar, standard deviation (SD). RQ; relative quantification. 
therefore interesting that according to our current results and previous findings, MIA2 and TANGO might behave as proto-oncogenes in SCCs of the esophagus, lung, and cervix $[19,20]$. These potential oncogenic roles might depend on receptor-related signaling differences. Indeed, we revealed that signaling through the MIA2-integrin $\alpha_{5} \beta_{1}$-JNK pathway promotes apoptosis, whereas signaling through the MIA2-integrin $\alpha_{4} \beta_{1}$-MAPK p38 pathway suppresses apoptosis [19]. Furthermore, MIA2 inhibits lymphocyte infiltration into tumors by binding integrin $\alpha_{4}$, thus dysregulating the host immune system [19]. Similar to MIA, MIA2 might also interact with fibronectin, which induces $\mathrm{T}$ lymphocyte chemotaxis when combined with stromal cell-derived factor $1 \alpha$ [31]; therefore, MIA or MIA2 might suppress $\mathrm{T}$ lymphocyte chemotaxis by masking fibronectin. TANGO expression is observed in many adult tissues [3]; we also confirmed weakly expression of TANGO in cancer-adjacent tissues (data not shown). In addition, we previously found that TANGO promotes tumor angiogenesis and lymphangiogenesis by activating PDGFB and neuropilin 2 [20]. Although TANGO is a ligand for CD11c/CD18 [5], we did not observe a direct interaction between TANGO and this receptor in OSCC cells [20]. More detailed studies will be needed to identify alternate receptors for TANGO in tumor cells; these might include other integrins or adhesion molecules.

In conclusion, we have demonstrated the utility of MIA gene family members as tumor markers, using a wide range of esophageal, lung, and cervical cancer samples. Although innumerable studies have investigated tumor biomarkers, the usefulness of molecular biomarkers for malignant tumors remains controversial. As $M I A$ gene family members are secretory proteins [3], they might be detectable in serum, saliva, urine, ascites, pleural fluid, and other samples that can be collected more easily than

\section{A}
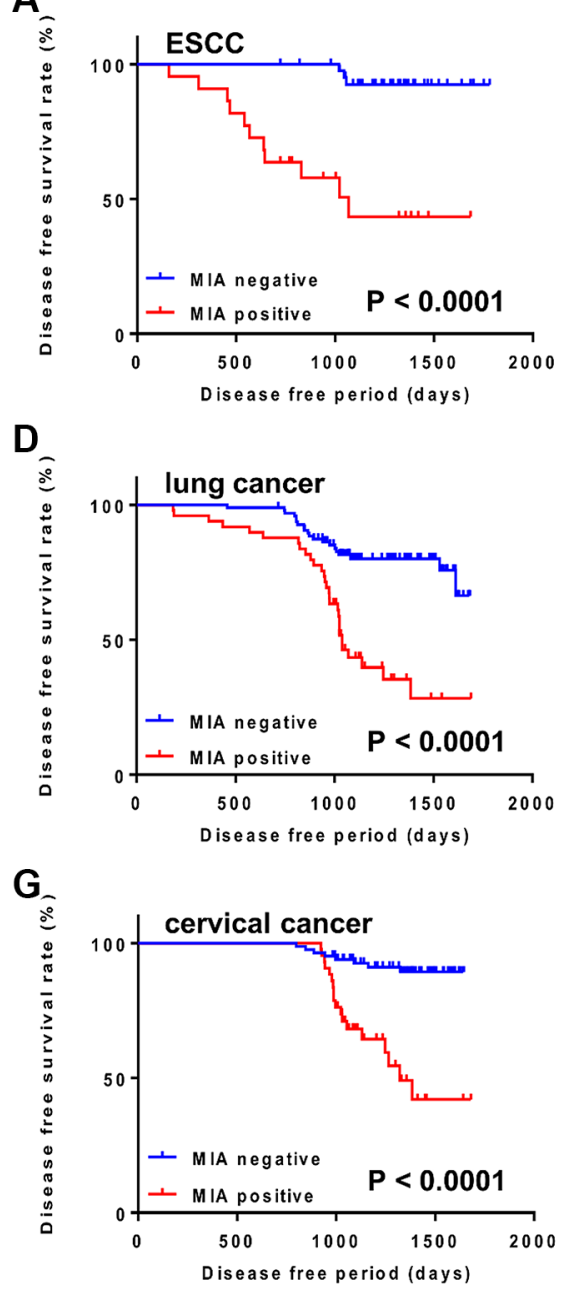
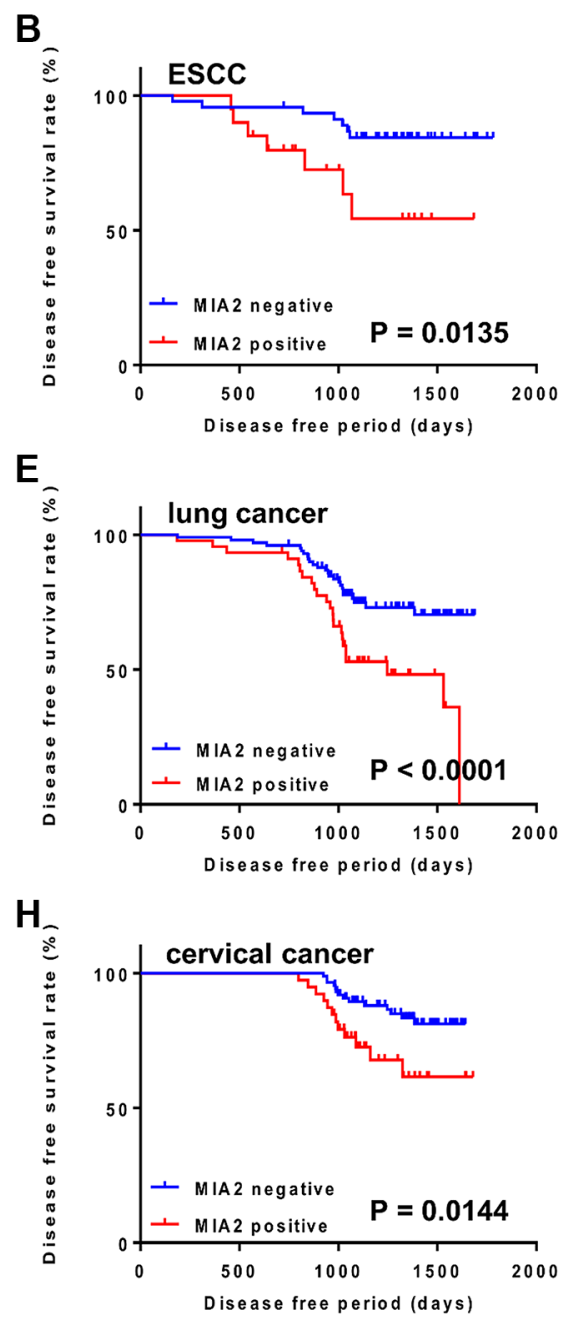
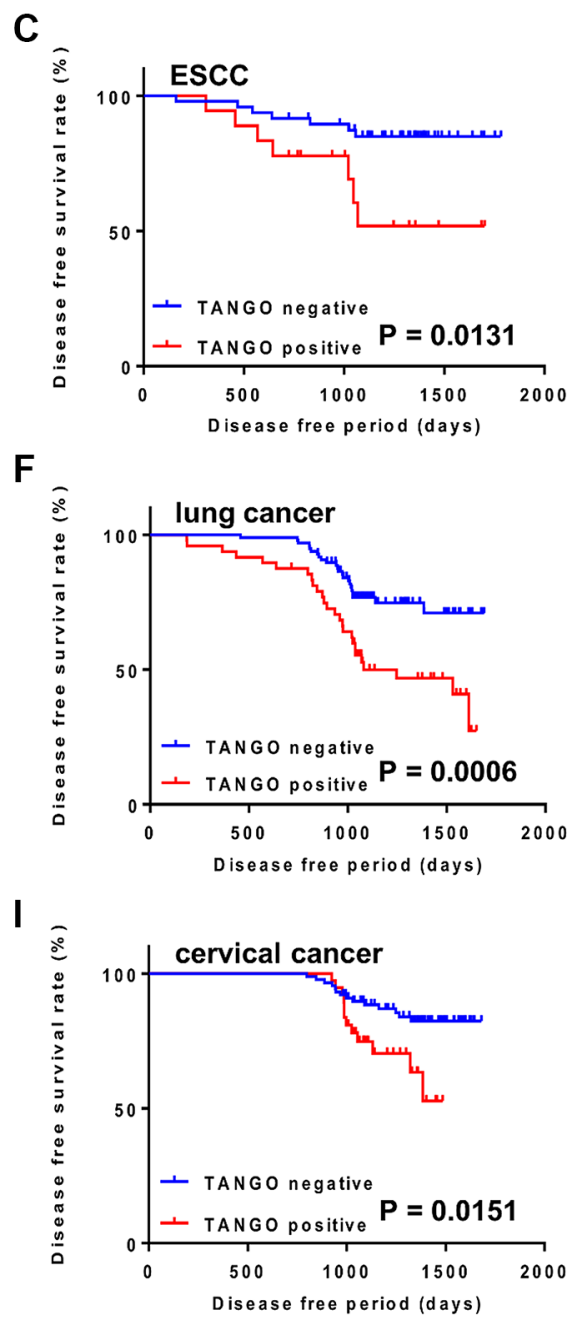

Figure 6: Disease free survival curves of cancer patients, as calculated by Kaplan-Meier method. (A-C) Disease free survival curves in ESCC cases. Disease free survival period was significantly shorter in patients with MIA (A), MIA2 (B), and TANGO (C) expression than in those with no expression. (D-F) Disease free survival curves in lung cancer cases. Cases with expression of MIA (D), MIA2 (E), and TANGO (F) had significantly worse prognosis than those with negative expression. (G-I) Disease free survival curves in cervical cancer cases. MIA (G), MIA2 (H), and TANGO (I) expression cases were correlated with poor prognosis. The $P$-value was calculated using the log-rank test. 
Table 4: Relationship between expression of MIA gene family and clinicopathological characteristics in cervical cancer

\begin{tabular}{|c|c|c|c|c|c|c|}
\hline \multirow[b]{2}{*}{ Parameters } & \multicolumn{2}{|c|}{ MIA } & \multicolumn{2}{|c|}{ MIA2 } & \multicolumn{2}{|c|}{ TANGO } \\
\hline & negative & positive & negative & positive & negative & positive \\
\hline \multicolumn{7}{|l|}{ Age } \\
\hline$<-60$ & 38 & 14 & 37 & 15 & 39 & 13 \\
\hline$>60$ & 45 & 29 & 50 & 24 & 49 & 25 \\
\hline$P$ value & 0.1835 & & 0.6999 & & 0.3287 & \\
\hline \multicolumn{7}{|l|}{ Histology* } \\
\hline CIN3 & 11 & 4 & 14 & 1 & 10 & 5 \\
\hline $\mathrm{SCC}$ & 72 & 39 & 73 & 38 & 78 & 33 \\
\hline$P$ value & 0.5777 & & 0.0361 & & 0.7704 & \\
\hline \multicolumn{7}{|c|}{ HPV16 and/or 18} \\
\hline Positive & 53 & 33 & 56 & 30 & 57 & 29 \\
\hline Negative & 33 & 10 & 31 & 9 & 31 & 9 \\
\hline$P$ value & 0.1131 & & 0.2147 & & 0.2192 & \\
\hline \multicolumn{7}{|l|}{ Clinical stage } \\
\hline $0-\mathrm{I}$ & 35 & 14 & 39 & 10 & 34 & 15 \\
\hline II & 43 & 19 & 38 & 24 & 46 & 16 \\
\hline III-IV & 5 & 10 & 10 & 5 & 8 & 7 \\
\hline$P$ value & 0.0177 & & 0.1145 & & 0.2861 & \\
\hline \multicolumn{7}{|l|}{ T classification } \\
\hline Tis-T1 & 34 & 14 & 38 & 10 & 33 & 15 \\
\hline $\mathrm{T} 2$ & 45 & 20 & 39 & 26 & 49 & 16 \\
\hline T3-4 & 4 & 9 & 10 & 3 & 6 & 7 \\
\hline$P$ value & 0.0185 & & 0.0755 & & 0.1087 & \\
\hline \multicolumn{7}{|c|}{ Nodal metastasis } \\
\hline Negative & 79 & 36 & 81 & 34 & 84 & 31 \\
\hline Positive & 4 & 7 & 6 & 5 & 4 & 7 \\
\hline$P$ value & 0.0477 & & 0.3135 & & 0.0175 & \\
\hline \multicolumn{7}{|c|}{ Distant metastasis } \\
\hline Negative & 80 & 40 & 84 & 36 & 87 & 33 \\
\hline Positive & 3 & 3 & 3 & 3 & 1 & 5 \\
\hline$P$ value & 0.4096 & & 0.3725 & & 0.0095 & \\
\hline
\end{tabular}

Relationship between expression of MIA genefamily and parameters were calculated by Fischer's exact test or chi-square test. T classification and clinical stage were classified according to the TNM classification.

*Histology: CIN3, cervical intraepithelial neoplasia 3; SCC, squamous cell carcinoma

tumors. Although additional detailed and large-scale examinations will be fundamental to determining the importance of $M I A$ gene family members in cancers, our findings indicate that these proteins are alternative and efficacious diagnostic and treatment targets in human cancers. Our results therefore provide new knowledge about molecular tumor markers that could potentially improve the clinical outcomes and quality of life of affected patients.

\section{MATERIALS AND METHODS}

\section{Tissue specimens}

Randomly selected formalin-fixed, paraffinembedded (FFPE) specimens were used for the present analysis. All FFPE samples were diagnosed at the Department of Molecular Pathology, Nara Medical University. To screen the expression of MIA family genes, 
we used a training cohort of 477 FFPE specimens in tumors of the following organs: 36 head and neck cancers, 15 salivary gland cancers, 10 esophageal cancers, 35 gastric cancers, 5 gastrointestinal tumors (GISTs) in the small intestine, 35 colorectal cancers, 16 liver cancers, 10 biliary cancers, 5 pancreatic cancers, 33 lung cancers, 33 bone and soft tissue malignant tumors, 3 skin malignant tumors, 19 breast cancers, 26 cervical cancers, 12 endometrial cancers, 47 ovarian cancers, 6 prostatic cancers, 11 testicular cancers, 17 bladder cancers, 16 kidney cancers, 15 thyroid cancers, 15 adrenal tumors, 20 malignant lymphomas, and 19 cancers of other tissues (Table 1).

Additionally, the validation set of $M I A$ gene family expression comprised FFPE esophageal cancer, cervical cancer, and lung cancer tissues. The details of specimens are as follows: 66 cases of ESCC (49 men and 17 women, age range: $47-80$ years, mean age $=67.5$ years $), 145$ cases of lung cancer (107 men and 38 women, age range: 45-83 years, mean age $=66.7$ years $)$, and 126 cases of cervical cancer (age range: $24-74$ years, mean age $=59.2$ years). The lung cancer cases were subclassified as follows: 105 squamous cell carcinomas (SCCs), 25 adenocarcinomas, 10 small cell carcinomas, and 10 large cell neuroendocrine carcinomas (LCNECs). The 126 cervical cancers included 15 cases of cervical intraepithelial neoplasia 3 (CIN3) and 111 of invasive SCC. Among all cases used for the validation set of $M I A$ gene family expression by immunohistochemistry, frozen and serum samples were available for gene expression and ELISA from cases with 10 ESCC, 14 lung cancer, and 13 cervical cancer, respectively. Each 5 samples of normal esophageal, lung, and cervical tissue and serum in healthy donor were used for control.

No patient received preoperative therapy. Tumor staging was performed according to the Union for International Cancer Control TNM classification system (seventh edition), and tumor histology was classified according to the World Health Organization criteria. Because written informed consent was not obtained for the immunohistochemical analysis, any identifying information was removed from the samples before the analysis to ensure the strict protection of patient privacy (unlinkable anonymizing). Written informed consent was obtained from individual patients for the use of their samples in the gene expression analysis and ELISA. The study plan was performed according to the ethical standards proposed in the Declaration of Helsinki and was approved by the Medical Ethics Committee of Nara Medical University, Kashihara, Japan (approval number. 719).

\section{Immunohistochemistry}

Consecutive $3-\mu \mathrm{m}$ sections were cut from each block and subjected to immunohistochemical staining with the EnVision+ DualLink system (DAKO, Carpinteria, CA, USA). After a 20-min antigen retrieval treatment with pepsin (DAKO), the sections underwent staining using an immunoperoxidase technique. Briefly, after a 15-min endogenous peroxidase block with $3 \% \mathrm{H}_{2} \mathrm{O}_{2}$-methanol, specimens were incubated in a $10 \%$ skim milk solution (Morinaga Milk, Tokyo, Japan) for $20 \mathrm{~min}$ to block non-specific antibody reactions and rinsed 3 times with phosphate-buffered saline (PBS) (Sigma-Aldrich, St. Louis, MO, USA). Anti-MIA (Santa Cruz Biotechnology, Santa Cruz, CA, USA), anti-MIA2 (Abcam, Tokyo, Japan), and anti-TANGO/MIA3 antibodies (LifeSpan, Seattle, WA, USA) were diluted to $1 \mu \mathrm{g} / \mathrm{ml}$ and used as primary antibodies; after a two hour primary antibody incubation, the sections were incubated with a secondary antibody for 30 minutes at room temperature. The specimens were subsequently rinsed three times with PBS and color-developed using a diaminobenzidine (DAB) solution (DAKO). After washing to remove excess DAB solution, the specimens were counterstained with Meyer's hematoxylin (Sakura Finetek Japan, Tokyo, Japan). All samples were immunostained under the same antibody reaction and $\mathrm{DAB}$ exposure conditions. Appropriate negative and positive control slides were used.

\section{Evaluation of immunohistochemistry}

MIA, MIA2, and TANGO immunoreactivities were classified according to the Allred's score (AS) [32]. We divided immunoreactivities into four grades based on AS: Grade 0, AS =0; Grade 1, AS = 2-4; Grade 2, AS =5-6; and Grade 3, AS =7-8. Grade 2 and 3 cases were considered immunologically positive, in accordance with our previous report [33].

\section{RNA extraction and qRT-PCR}

Total RNA was extracted using TRIzol reagent (Invitrogen, Carlsbad, CA, USA), and $1 \mathrm{mg}$ of total RNA was converted to cDNA with a ReverTra Ace qPCR RT Kit (Toyobo, Osaka, Japan). Real-time RT-PCR was performed on a StepOnePlus Real-Time PCR System (Applied Biosystems, Foster City, CA, USA) using TaqMan Fast Universal PCR Master Mix (Applied Biosystems), and analyzed using the relative standard curve quantification method. The PCR conditions used were selected according to the manufacturer's manual and glyceraldehyde-3-phosphate dehydrogenase (GAPDH) mRNA was amplified as an internal control. TaqMan Gene Expression Assays of MIA (Hs00197954_m1), MIA2 (Hs00365015_m1), MIA3 (TANGO) (Hs00412706 $\mathrm{m} 1$ ), and GAPDH (ID: Hs03929097_g1) were purchased from Applied Biosystems. All PCRs were performed in triplicate.

\section{ELISA for MIA}

The serum samples were obtained before treatment and stored at $-80^{\circ} \mathrm{C}$. Serum levels of MIA were measured by ELISA system for MIA (Roche Diagnostics, 
Mannheim, Germany) according to the manufacturer's instructions. All samples were tested in triplicate.

\section{Statistical analysis}

Relationships between MIA gene family expression and clinicopathological parameters were calculated using the chi-square test or Fisher's exact test. Disease free survival was analyzed according to the Kaplan-Meier method, and differences between groups were calculated using a log-rank test. JMP8 software (SAS Institute, Cary, NC, USA) was used for all statistical analyses. $P$ values $<0.05$ were considered statistically significant.

\section{ACKNOWLEDGMENTS AND FUNDING}

This work was supported in part by Grant-in-Aid for Scientific Research from Japan Society for the Promotion of Science, Japan.

\section{CONFLICTS OF INTEREST}

We declare that there is not any Financial Support or Relationships which may pose a conflict of interest in the contents of the submitted manuscript.

\section{REFERENCES}

1. Torre LA, Bray F, Siegel RL, Ferlay J, Lortet-Tieulent J, Jemal A. Global cancer statistics, 2012. CA Cancer J Clin. $2015 ; 65: 87-108$.

2. Jia Y, Wang N, Wang J, Tian H, Ma W, Wang K, Tan B, Zhang G, Yang S, Bai B, Cheng Y. Down-regulation of stromal caveolin-1 expression in esophageal squamous cell carcinoma: a potent predictor of lymph node metastases, early tumor recurrence, and poor prognosis. Ann Surg Oncol. 2014; 21:329-336.

3. Bosserhoff AK, Moser M, Buettner R. Characterization and expression pattern of the novel MIA homolog TANGO. Gene expression patterns: GEP. 2004; 4:473-479.

4. Arndt S, Bosserhoff AK. TANGO is a tumor suppressor of malignant melanoma. Int J Cancer. 2006; 119:2812-2820.

5. Arndt S, Melle C, Mondal K, Klein G, von Eggeling F, Bosserhoff AK. Interactions of TANGO and leukocyte integrin $\mathrm{CD} 11 \mathrm{c} / \mathrm{CD} 18$ regulate the migration of human monocytes. J Leukocyte Biol. 2007; 82:1466-1472.

6. Arndt S, Bosserhoff AK. Reduced expression of TANGO in colon and hepatocellular carcinomas. Oncol Rep. 2007; 18:885-891.

7. Bosserhoff AK, Buettner R. Expression, function and clinical relevance of MIA (melanoma inhibitory activity). Histol Histopathol. 2002; 17:289-300.

8. Bosserhoff AK, Kaufmann M, Kaluza B, Bartke I, Zirngibl H, Hein R, Stolz W, Buettner R. Melanoma- inhibiting activity, a novel serum marker for progression of malignant melanoma. Cancer Res. 1997; 57:3149-3153.

9. Bosserhoff AK, Stoll R, Sleeman JP, Bataille F, Buettner R, Holak TA. Active detachment involves inhibition of cellmatrix contacts of malignant melanoma cells by secretion of melanoma inhibitory activity. Lab Invest. 2003; 83: $1583-1594$.

10. El Fitori J, Kleeff J, Giese NA, Guweidhi A, Bosserhoff AK, Buchler MW, Friess H. Melanoma Inhibitory Activity (MIA) increases the invasiveness of pancreatic cancer cells. Cancer cell international. 2005; 5:3.

11. Aung PP, Oue N, Mitani Y, Nakayama H, Yoshida K, Noguchi T, Bosserhoff AK, Yasui W. Systematic search for gastric cancer-specific genes based on SAGE data: melanoma inhibitory activity and matrix metalloproteinase-10 are novel prognostic factors in patients with gastric cancer. Oncogene. 2006; 25:2546-2557.

12. Winklmeier A, Contreras-Shannon V, Arndt S, Melle C, Bosserhoff AK. Cadherin-7 interacts with melanoma inhibitory activity protein and negatively modulates melanoma cell migration. Cancer Sci. 2009; 100:261-268.

13. Bosserhoff AK, Moser M, Scholmerich J, Buettner R, Hellerbrand C. Specific expression and regulation of the new melanoma inhibitory activity-related gene MIA2 in hepatocytes. J Biol Chem. 2003; 278:15225-15231.

14. Hellerbrand C, Bataille F, Schlegel J, Hartmann A, Muhlbauer M, Scholmerich J, Buttner R, Hofstadter F, Bosserhoff AK. In situ expression patterns of melanoma inhibitory activity 2 in healthy and diseased livers. Liver international. 2005; 25:357-366.

15. Hellerbrand C, Amann T, Schlegel J, Wild P, Bataille F, Spruss T, Hartmann A, Bosserhoff AK. The novel gene MIA2 acts as a tumour suppressor in hepatocellular carcinoma. Gut. 2008; 57:243-251.

16. Kong B, Wu W, Valkovska N, Jager C, Hong X, Nitsche U, Friess H, Esposito I, Erkan M, Kleeff J, Michalski CW. A common genetic variation of melanoma inhibitory activity-2 labels a subtype of pancreatic adenocarcinoma with high endoplasmic reticulum stress levels. Scientific reports. 2015; 5:8109.

17. Sasahira T, Kirita T, Oue N, Bhawal UK, Yamamoto K, Fujii K, Ohmori H, Luo Y, Yasui W, Bosserhoff AK, Kuniyasu H. High mobility group box-1-inducible melanoma inhibitory activity is associated with nodal metastasis and lymphangiogenesis in oral squamous cell carcinoma. Cancer Sci. 2008; 99:1806-1812.

18. Sasahira T, Kirita T, Kurihara M, Yamamoto K, Bhawal UK, Bosserhoff AK, Kuniyasu H. MIA-dependent angiogenesis and lymphangiogenesis are closely associated with progression, nodal metastasis and poor prognosis in tongue squamous cell carcinoma. Eur J Cancer. 2010; 46:2285-2294.

19. Kurihara M, Kirita T, Sasahira T, Ohmori H, Matsushima S, Yamamoto K, Bosserhoff AK, Kuniyasu H. Protumoral roles of melanoma inhibitory activity 2 in oral squamous 
cell carcinoma. Br J Cancer. 2013; 108:1460-1469.

20. Sasahira T, Kirita T, Yamamoto K, Ueda N, Kurihara M, Matsushima S, Bhawal UK, Bosserhoff AK, Kuniyasu H. Transport and Golgi organisation protein 1 is a novel tumour progressive factor in oral squamous cell carcinoma. Eur J Cancer. 2014; 50:2142-2151.

21. Biomarkers Definitions Working G. Biomarkers, surrogate endpoints: preferred definitions and conceptual framework. Clin Pharmacol Ther. 2001; 69:89-95.

22. Sasahira T, Kirita T, Kuniyasu H. Update of molecular pathobiology in oral cancer: a review. International journal of clinical oncology. 2014; 19:431-436.

23. Wu JY, Yi C, Chung HR, Wang DJ, Chang WC, Lee SY, Lin CT, Yang YC and Yang WC. Potential biomarkers in saliva for oral squamous cell carcinoma. Oral Oncol. 2010; 46:226-231.

24. Ikota H, Nobusawa S, Tanaka Y, Yokoo H and Nakazato Y. High-throughput immunohistochemical profiling of primary brain tumors and non-neoplastic systemic organs with a specific antibody against the mutant isocitrate dehydrogenase 1 R132H protein. Brain Tumor Pathol. 2011; 28:107-114.

25. Jachimczak P, Apfel R, Bosserhoff AK, Fabel K, Hau P, Tschertner I, Wise P, Schlingensiepen KH, SchulerThurner B, Bogdahn U. Inhibition of immunosuppressive effects of melanoma-inhibiting activity (MIA) by antisense techniques. Int J Cancer. 2005; 113:88-92.

26. Bauer R, Humphries M, Fassler R, Winklmeier A, Craig SE, Bosserhoff AK. Regulation of integrin activity by MIA. J Biol Chem. 2006; 281:11669-11677.

27. Graf SA, Busch C, Bosserhoff AK, Besch R, Berking C. SOX10 promotes melanoma cell invasion by regulating melanoma inhibitory activity. J Invest Dermatol. 2014; 134:2212-2220.
28. Bosserhoff AK, Moser M, Hein R, Landthaler M, Buettner R. In situ expression patterns of melanomainhibiting activity (MIA) in melanomas and breast cancers. J Pathol. 1999; 187:446-454.

29. Bosserhoff AK, Kondo S, Moser M, Dietz UH, Copeland NG, Gilbert DJ, Jenkins NA, Buettner R, Sandell LJ. Mouse CD-RAP/MIA gene: structure, chromosomal localization, and expression in cartilage and chondrosarcoma. Dev Dyn. 1997; 208:516-525.

30. Hau P, Ruemmele P, Kunz-Schughart LA, Doerfelt A, Hirschmann B, Lohmeier A, Koch H, Mueller A, Bogdahn U, Bosserhoff AK. Expression levels of melanoma inhibitory activity correlate with time to progression in patients with high-grade glioma. Oncol Rep. 2004; 12:1355-1364.

31. Savino W, Mendes-da-Cruz DA, Silva JS, Dardenne M, Cotta-de-Almeida V. Intrathymic T-cell migration: a combinatorial interplay of extracellular matrix and chemokines? Trends Immunol. 2002; 23:305-313.

32. Allred DC, Harvey JM, Berardo M, Clark GM. Prognostic and predictive factors in breast cancer by immunohistochemical analysis. Mod Pathol. 1998; 11: 155-168.

33. Sasahira $T$, Ueda $N$, Yamamoto $K$, Kurihara $M$, Matsushima S, Bhawal UK, Kirita T, Kuniyasu H. Prox1 and $\mathrm{FOXC2}$ act as regulators of lymphangiogenesis and angiogenesis in oral squamous cell carcinoma. PLoS ONE. 2014; 9:e92534. 